although the main principles are well set out as is the influence which the various experimental parameters will have on the choice of method for a particular type of problem. Each chapter has its own bibliography and there is a helpful subject-index, but the treatment does not lend itself to an index of chemicals. A collected list of symbols would be an improvement in subsequent editions. The style is clear and vigorous, and the text is full of interesting speculations. All workers in gas chromatography will find it stimulating reading, and with its emphasis on principlos it should be particularly suited to students.

C. S. G. Phillips

\section{REVIEWS OF PHARMACOLOGY}

Annual Review of Pharmacology

Vol. 2. Edited by Windsor C. Cutting, in association with Robert H. Dreisbach and Henry W. Elliott. Pp. vi +477 . (Palo Alto, Calif.: Annual Reviews, Inc., 1962.) 7 dollars.

THE second Annual Review of Pharmacology adheres to the form which has been so successful in the longer ostablished series of Annual Reviews in biochemistry, in physiology and in medicine. There can be no question of the value of Annual Reviews to research workers and to teachers; however, there are those who would prefer a slightly different presentation. The lists of references given at the end of each review article are numbered, sometimes in alphabetical order sometimes in the order in which they appear in the text; standardization would ease the reader's task. In the text the references are given sometimes as the author's name followed by the number of the reference and sometimes by the number alone; if the reader wishes to know who was the author in the latter case, it is necessary to turn to the end of the article. The question of dates of publications is important, particularly when the reviewers refer to a number of related investigations. Although these are Annual Reviews, by no means every field is covered annually, in fact, the literature cited usually covers periods of 5-20 years: in one article the earliest publication cited is 1821 while in another it is 1959 .

There is much to recommend to the publishers of Annual Reviews another commonly used system of citing references: to give in the text the names of the author(s) followed by the year of publication, and to arrange the list of references alphabetically. Since library facilities for most readers are far from perfect an additional convenience would follow if the titles of the papers were given, preferably in their original language, or if translated, with the original language indicated.

Of the articles in the present volume, Dr. Gaddum's history, "The Pharmacologists of Edinburgh" is the only one that can be read with enjoyment by the non-specialist. Chancey Leake's "Review of Reviews" is also of general interest. The reviews on the pharmacology of China, India and Central Europe are valuable in diverting attention outwards from the American-Western European pharmacological nexus. It is to be regretted that the international situation is such that Chinese pharmacology was not roviewed by a pharmacologist working in China. Dr. Chen's review was heavily weighted towards practical medicine, presumably reflecting the Chinese literature; perhaps this is as it should be in a rapidly emerging nation.

Each of the remaining thirteen review articles deals competently with various specialized aspects of pharmacology. Most of the contributors admit to some degree of selection in referring to the literature: clearly this is unavoidable if Annual Reviews is to be more than another abstracting service. On the other hand, a critical assessment of published literature has been attempted by only some of the contributors. If the objects of Annual
Reviews are to collect together the most important recently published work in given fields, but to avoid presenting the opinion of the reviewers, they have been successfully achieved. M. J. RAND

\section{SCIENCE AND DEFENCE POLICY}

\section{The Rise of the Boffins}

By Ronald W. Clark. Pp. xix $+268+16$ plates. (London: Phoenix House, Ltd., 1962.) 25s. net.

M R. CLARK, who was a war correspondent with the 1 Canadians, gives us in this book a vivid account of the influence of science on defence policy, and more particularly of the relations between scientists themselves in that field and between scientists and the Services. It is far more than a competent piece of journalism; whil he is concerned largely with personalities, they are not allowed to become obsessive, and the Tizard-Cherwell clash is handled with fairness and judgment in which the author's own leanings are obvious but not allowed to obscure the issues. It may not be a scholar's book, and it is written in a style which should deservedly commend a popular as well as scientific audience. Nevertheless, although Mr. Clark relies in this book very largely on unpublished material, including the archives of the Royal Society, and the help of many of those concerned with the events with which he deals, his book is better documentated than many more pretentious works. Apart possibly from Tizard's own Haldane Memorial Lecture and Messel Memorial Lecture, his brief bibliography omits scarcely a major reference although, admittedly, as regards the development of relations between scientists and the Services during the First World War, much material is scattered through autobiographies and biographies of the type of Sir Froderick Sykes's From Many Angles, on which it is a matter of opinion as to whether it should or should not be included.

As a piece of exposition, the book could not easily be bettered, and scientists themselves would do well to note this demonstration of the practicability of easy communication free from jargon; even the curse of abbrevia. tions is held tightly and reasonably in check. It is also a useful contribution to the study of the interrelations between the scientist and public affairs, correcting, for example, a certain imbalance in Lord Hailsham's recent book, Science and Politics, and not the less effectively because Mr. Clark never assays specifically to discuss such general issues. From his brief initial account of interrelations during the First World War his chapters describe successively and fluently the development of relations during the inter-war years to the establishment of radar and the first crude attempts to mobilize Britain's scientific resources at the onset of war. Specific contribution. of science, both defensive and offensive, are clearly described as the account continues into the war years, and technical details are not allowed either to daunt the general reader, or to cover weaknesses or failures in system or personality at various levels. It underlines much that is soundest in Sir Charles Snow's lectures on "Science and Government" and in Lord Hailsham's more recent book, illustrating, for example, the crucial importance of the three desiderata which the Minister for Science lays down for Britain's educational system. It is not for a book of this character to describe, much less prescribe, the means, or the mechanism of decision; there could, however, be no more effective demonstration of the imperative necessity for roason to be at the cutting edge, and the suggestion that reason indicates that the best solution to most defence problems often lies in not going to war at all in no way detracts from that domonstra. tion.

$\mathrm{It}$ is a pity that the author uses the vulgar expression 'boffins'. 